\title{
Colonic Atresia and Hirschsprung's Disease: A Case Report from King Abdulaziz University Hospital
}

\author{
Nouf Y. Akeel, SBS, Jamal S. Kamal, FRCSI, FACS, and Aisha M. Abdulrahman, MBBS \\ Department of Surgery, Faculty of Medicine, \\ King Abdulaziz University, Jeddah, Saudi Arabia
}

\author{
Correspondence \\ Dr. Nouf Y. Akeel \\ Department of Surgery \\ Faculty of Medicine \\ King Abdulaziz University \\ P.O. Box 80215, Jeddah 21589, Saudi Arabia \\ e.M: nakeel@ka.edu.sa \\ Submission: 17 November 2014 \\ Accepted: 16 December 2014

\section{Citation} \\ Akeel NY, Kamal JS, Abdulrahman AM. Colonic \\ atresia and Hirschsprung's disease: A case \\ report from King Abdulaziz University Hospital. \\ JKAU Med Sci 2015; 22(1): 65-68.
}

\begin{abstract}
Atresia of the colon is a rare form among all types of intestinal atresia. However, the association between colonic atresia and aganglionosis is extremely rare; it may be easily overlooked due to the associated distal microcolon. Management of a case of colonic atresia with distal aganglionosis presented with anastomotic leak due to unsuspected aganglionosis will be discussed.
\end{abstract}

\section{Keywords}

Colonic atresia, Aganglionosis, Anastomotic leak.

\section{Introduction}

Colonic atresia is the least common site of intestinal atresia ${ }^{[1]}$. It has been reported to be associated with many congenital anomalies ${ }^{[1,2]}$. The association with Hirschsprung's disease is very uncommon and may be associated with significant morbidity and mortality ${ }^{[3]}$. As a result of absent flow of contents, the distal segment in bowel atresia remains hypoplastic, similar to aganglionic segment. When both conditions occur in association, the management usually goes to the atresia and the distal aganglionosis could be overlooked.

We are reporting a case of male infant with colonic atresia in which the diagnosis of associated Hirschsprung's disease was not identified early.

\section{Case Report}

A baby boy was born in another hospital with colonic atresia for which he had resection and end-to-end anastomosis and transverse colostomy. At the age of 3 months, he had colostomy closure but unfortunately he developed anastomotic leak. Two days after colostomy closure, he presented to our emergency room with, abdominal distension, fever, tachycardia, and tachypnea. On examination, he was dehydrated; febrile but maintained blood pressure. The abdomen was tense and massively distended with no audible bowel sounds. Routine blood works were unremarkable. Chest and abdominal X-rays have revealed pneumoperitoneum.

After resuscitation, he was taken to the operating room for laparotomy. At exploration, a pocket of pus was found in the right iliac fossa with a small leak at the site of anastomosis. The colonic segment distal to the anastomosis looks narrower than the proximal one. The leaking site was closed primarily with 5-0 vicryl and peritoneal lavage was done. However, he had a stormy postoperative course over the following days: An increase in the abdominal girth and unstable hemodynamic status. CT scan of the abdomen showed multiple collections in the peritoneal cavity.

On day five postoperative, he was taken again to the operating room, there was another perforation at the same site. At this stage, it was decided to exteriorize 
the anastomosis and defunct of the distal colon with multiple biopsies. He had an uneventful recovery. The histopathology report confirmed absence of ganglion cells in all segments distal to the anastomosis. He was discharged home well then brought again seven months later for Swenson pull through. He was followed up in the clinic for three years with no significant complaints.

\section{Discussion}

The colon is the least common site of atresia in the gastrointestinal tract. It accounts for 5 to $15 \%$ of intestinal atresias. Colonic atresia can be associated with various anomalies like abdominal wall defects, abnormalities of the genitourinary tract, anal atresia, imperforate anus and many other anomalies like cryptophthalmos syndrome (i.e., cleft lip and palate, microphthalmia, dysplastic kidneys, and proximal jejunal atresia), arthrogryposis, proximal intestinal atresia, neoplasm, and malrotation ${ }^{[1-7]}$.

The association of colonic atresia with Hirschsprung's disease is extremely uncommon $2 \%{ }^{[8]}$. Hyde et al ${ }^{[9]}$ has reported the first case in 1968 . Early recognition of this association is important and requires special attention to avoid the morbidity, and mortality as the coexistence of these two pathology carries a $10 \%$ mortality rate ${ }^{[3,10]}$.

The pathophysiology of this association is explained by the theory of intrauterine vascular accident, which occurs during early pregnancy and leads to intestinal ischemia. This results in colonic atresia, which acts as a mechanical barrier to the migration of neural crest cells thus resulting in aganglionosis in the post atretic segment ${ }^{[11,12]}$. Conversely, the association can be explained by the presence of Hirschsprung's disease leading to the torsion of the dilated proximal ganglionic segment resulting in colonic atresia[13,14]. Other possible theories are the presence of the defect involving vasoconstrictor peptides and endothelin pathway and the theory of chance association ${ }^{[10,15]}$.

In addition to its rarity, the similarity in clinical and radiological presentation of colonic atresia and Hirschsprung's disease makes early diagnosis difficult ${ }^{[12]}$.

In most of the reported cases, where the early diagnosis was missed, the cases presented after colocolonic anastomosis with features of delayed return of bowel movement or anastomotic failure, resulting in an increased morbidity ${ }^{[7,12,13,16]}$. In those reported cases, the delay in recognizing the associated Hirschsprung's disease is due to lack of histopathological examination of the distal colon ${ }^{[10]}$. Akgür et al. ${ }^{[17]}$ reported a case of early diagnosed Hirschsprung's disease in a patient with colonic atresia in which biopsies were taken from the distal colon before reestablishing intestinal continuity, which eliminated the postoperative morbidity.
Hirschsprung's disease should be suspected in all forms of bowel atresias, and colonic atresia patients in particular ${ }^{[13]}$. The complicated and protracted clinical course of the reported cases of this association support the need of routine histopathological examination, of both pre and post atretic colonic segment to preclude the possibility of Hirschsprung's disease ${ }^{[18-22]}$.

Reviewing the reported cases of colonic atresia associated with Hirschsprung's disease suggested that the aganglionosis might be suspected by the presence of a foreshortened, nonfixed colon coiled in the pelvis ${ }^{[23,24]}$. However, Draus et al. ${ }^{[3]}$ reported the presence of normally oriented colon in a patient with colonic atresia associated with Hirschsprung's disease. Patients with colonic atresia, regardless of distal colonic orientation, should be considered for rectal and colonic biopsies before restoration of intestinal continuity ${ }^{[15]}$.

\section{Conclusion}

Hirschsprung's disease should be suspected in cases of colonic atresia and all forms of bowel atresia. Although it's rare to have this association, we recommend rectal biopsies before establishing intestinal continuity in all cases of colonic atresia to avoid the devastating course of management from the delayed recognition of Hirschsprung's disease.

\section{References}

[1] Powell RW, Raffensperger JG. Congenital colonic atresia. J Pediatr Surg 1982; 17(2): 166-170.

[2] Cox SG, Numanoglu A, Millar AJ, Rode H. Colonic atresia: spectrum of presentation and pitfalls in management. A review of 14 cases. Pediatr Surg Int 2005; 21(10): 813-818.

[3] Draus JM Jr, Maxfield CM, Bond SJ. Hirschsprung's disease in an infant with colonic atresia and normal fixation of the distal colon. J Pediatr Surg 2007; 42(2): e5-8.

[4] Wang KS, Cahill JL, Skarsgard ED. Omphalocele, colonic atresia, and Hirschsprung's disease: an unusual cluster of malformations in a single patient. Pediatr Surg Int 2001; 17(23): $218-220$

[5] Nitta K, Iwafuchi M, Ohsawa Y, Uchiyama M, Yamagiwa I, Hirota M, Naito M, Hirokawa K. A case of congenital colonic atresia associated with atresia ani. J Pediatr Surg 1987; 22(11): 1025-1026.

[6] Asabe K, Nagasaki A. Double atresia of the hindgut with ileal stenosis: a case report. Asian J Surg 2004; 27(1): 49-51.

[7] Zundel S, Obermayr F, Schaefer JF, Fuchs J. Hirschsprung disease associated with total colonic agenesis and imperforate anus - case report and review of the literature. J Pediatr Surg 2010; 45(1): 252-254.

[8] Oldham KT, Arca MJ. Atresia, stenosis and other obstructions of the colon. In: Pediatric Surgery Vol. 2. J. O'Neill, A. Coran, E. Fonkalsrud, \& J. Grosfeld (ed.), 6 ed, Philadelphia: Mosby, 2006. 1493-500 
[9] Hyde GA Jr, De Lorimier AA. Colon atresia and Hirschsprung's disease. Surgery 1968; 64(5): 976-978.

[10] Sharma SB, Gupta V, Sharma V. Hirschsprung's disease complicating colonic atresia. Indian J Pediatr 2004; 71(5): 445-446.

[11] Akgür FM, Tanyel FC, Büyükpamukçu N, Hiçsönmez A. Colonic atresia and Hirschsprung's disease association shows further evidence for migration of enteric neurons. J Pediatr Surg 1993; 28(4): 635-636.

[12] Kim PC, Superina RA, Ein S. Colonic atresia combined with Hirschsprung's disease: a diagnostic and therapeutic challenge. J Pediatr Surg 1995; 30(8): 1216-1217.

[13] Seo T, Ando H, Watanabe Y, Harada T, Ito F, Kaneko K, Katsuno S, Marui Y, Ochiai K. Colonic atresia and Hirschsprung's disease: importance of histologic examination of the distal bowel. J Pediatr Surg 2002; 37(8): E19.

[14] Currie AB, Hemalatha AH, Doraiswamy NV, Cox SA. Colonic atresia associated with Hirschsprung's disease. J R Coll Surg Edinb 1983; 28(1): 31-34.

[15] Croaker GD, Harvey JG, Cass DT. Hirschsprung's disease, colonic atresia, and absent hand: a new triad. J Pediatr Surg 1997; 32(9): 1368-1370.

[16] Johnson JF, Dean BL. Hirschsprung's disease coexisting with colonic atresia. Pediatr Radiol 1981; 11(2): 97-98.

[17] Akgür FM, Olguner M, Hakgüder G, Ozer E, Aktuğ T. Colonic atresia associated with Hirschsprung's disease: it is not a diagnostic challenge. Eur J Pediatr Surg 1998; 8(6): 378-379.

[18] Hsu CT, Wang SS, Houng JF, Chiang PJ, Huang CB. Congenital colonic atresia: report of one case. Pediatr Neonatol 2010; 51(3): 186-189.

[19] Wisbach GG, Vazquez WD. Ileal atresia, malrotation and Hirschsprung's disease: A case report. J Ped Surg Case Reports 2013; 1(1): e3-e5.

[20] Corduk N, Koltuksuz U, Bir F, Karabul M, Herek O, SariogluBuke A. Association of rare intestinal malformations: colonic atresia and intestinal neuronal dysplasia. Adv Ther 2007; 24(6): 1254-1259.

[21] Moore SW, Rode H, Millar AJ, Cywes S. Intestinal atresia and Hirschsprung's disease. Pediatr Surg Int 1990; 5(3): 182-184.

[22] Haffner JF, Schistad G. Atresia of the colon combined with Hirschsprung's disease A case report. J Pediatr Surg 1969; 4(5): 560-562.

[23] Fishman SJ, Islam S, Buonomo C, Nurko S. Nonfixation of an atretic colon predicts Hirschsprung's disease. J Pediatr Surg 2001; 36(1): 202-204.

[24] Landes A, Shuckett B, Skarsgard E. Non-fixation of the colon in colonic atresia: a new finding. Pediatr Radiol 1994; 24(3): 167-169. 


\title{
رتق القولون وانعدام الخلايا العقدية شديد الندرة: تقرير عن حالة من مستشفى جامعة الملك عبدالعزيز
}

\author{
نوف يحيى عقيل، وجمال صديق كمال، وعائشة محمد عبدالرحمن

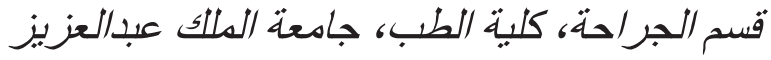

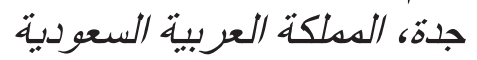

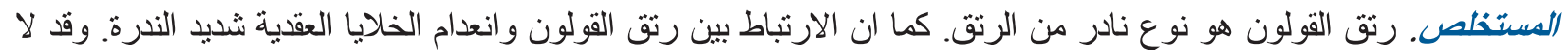

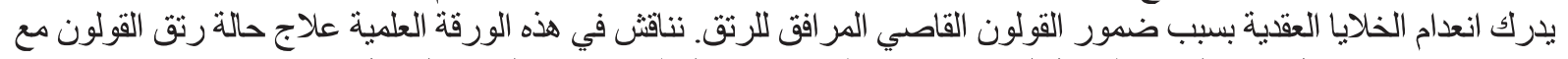

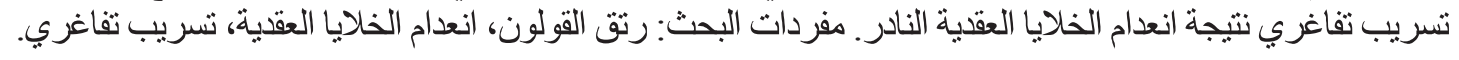

